\title{
A GEOGRAFIA AGRÁRIA BRASILEIRA: DINÂMICA, VARIADA E COMPLEXA
}

\section{Brazilian Agricultural Geography - Dynamics, Varied and Complex}

Prof $^{a}$. Dr ${ }^{\text {a }}$. Darlene Aparecida de Oliveira Ferreira

Universidade Estadual Paulista Júlio de Mesquita Filho/ RC Av. 24A, 1515 Campus, CEP: 13506-900 - Rio Claro (SP), Brasil Tél.: (+ 55 19) 35269222 - darlene@rc.unesp.br

\section{$a \cap \boldsymbol{a} a$}

\begin{abstract}
Resumo
O presente texto pretende ser uma contribuição ao debate sobre as questões metodológicas em torno da Geografia Agrária, demonstrando porque a Geografia Agrária brasileira é dinâmica, variada e complexa. Escolheu-se como tema os Grupos de Pesquisa em Geografia Agrária presentes no Diretório de Grupos do CNPq e sobre eles realizou-se uma caracterização considerando: instituição sede, localização por região geográfica, ano de formação, nome do Grupo, linhas de pesquisa e palavras-chave das linhas. O levantamento realizado permitiu o tratamento de 70 grupos de pesquisa que em 2009 tinham a geografia agrária, a agricultura, o desenvolvimento rural, o rural, o mundo rural, a organização do espaço e o desenvolvimento rural como norteadores de suas pesquisas e atuações. A análise das linhas de pesquisa permitiu identificar Grupos de Pesquisa preocupados com questões econômicas, políticas, ecológicas, demográficas e culturais, e para, além disso, encontramos preocupações com os produtores rurais, com as suas produções e com o funcionamento do sistema agropecuário, sendo assim, do conjunto de linhas levantadas é possível afirmar que há uma diversidade significativa em temas, o que reforça a hipótese da dinamicidade, variedade e complexidade dos estudos sobre agricultura na atualidade.
\end{abstract}

Palavras-chave: Grupos de pesquisa, discussões metodológicas, geografia agrária, agricultura, rural.

\begin{abstract}
This paper is a contribution to the debate on the methodological issues surrounding the Land Geography, demonstrating why the Brazilian Agrarian Geography is dynamic, varied and complex. It was chosen as the theme of Research Groups in Geography Agrarian present in Directory Groups CNPq and they held on a characterization considering: home institution, location, year of training, Group name, words and lines of research. The survey allowed the treatment of 70 groups in 2009 had the agrarian geography, agriculture, rural development, rural, rural areas, organization of space and rural development as guiding their research and performances. The analysis of the research lines identified groups concerned with economic, political, ecological, demographic and cultural, and also found concerns with farmers, with their production and the functioning of the agricultural system, being thus, the set of raised lines one can say that there is significant diversity in themes, which reinforces the hypothesis of dynamism, variety and complexity of studies on agriculture today.
\end{abstract}

Key words: Research groups, methodological discussions, agrarian geography, agriculture, rural.

\section{Resumen}

El presente texto pretende ser una contribución al debate sobre las cuestiones metodológicas en torno de la Geografía Agraria, demostrando porque la Geografía Agraria brasileña es dinámica, variada y compleja. Se escogió como tema los Grupos de Investigación en Geografía Agraria presentes en el Directorio de Grupos del CNPq y sobre ellos se realizó una caracterización considerando: institución sede, localización por región geográfica, año de formación, nombre del Grupo, líneas de investigación y palabras-clave de las líneas. El levantamiento realizado permitió el tratamiento de 70 grupos de investigación que en 2009 existían en la geografía agraria, la agricultura, el desarrollo rural, el rural, el mundo rural, la organización del espacio y el desarrollo rural como guías de sus investigaciones y acciones. El análisis de las líneas de investigación permitió identificar Grupos de Investigación preocupados con cuestiones económicas, políticas, ecológicas, demográficas y culturales, $\mathrm{y}$, además de eso, encontramos preocupaciones con los productores rurales, con sus trabajos y con el funcionamiento del sistema agropecuario, siendo esto, del conjunto de líneas levantadas es posible afirmar que hay una diversidad significativa en temas, lo que refuerza la hipótesis de la dinamicidad, variedad y complexidad de los estudios sobre agricultura en la actualidad.

Palabras clave: Grupos de investigación, discusiones metodológicas, geografía agraria, agricultura, rural.

\section{åaa}

Revista da ANPEGE, v. 7, n. 7, p. 83-96, jan./jul. 2011.

ISSN 1679-768 X @ (2003, Associação Nacional de Pesquisa e Pós-Graduação em Geografia. Todos os direitos reservados. 


\section{INTRODUÇÃO}

O presente texto pretende ser uma contribuição ao debate sobre as questões metodológicas em torno da Geografia Agrária. A proposta aqui colocada é bastante ampla e deverá produzir discussões em diferentes enfoques. Discutir questões metodológicas configura-se como um trabalho exaustivo, que merece uma avaliação quantitativa e qualitativa, a ser realizada de forma contínua.

Em um rápido levantamento realizado junto ao Diretório dos Grupos de Pesquisa no Brasil do CNPq é possível observar que dinâmica (agrária, territorial, regional) e dinamismo (agrícola, produtivo) são termos frequentes nas linhas de pesquisa e nas palavras-chave que as definem e retratam sem dúvida o que é a Geografia Agrária brasileira.

Dinâmica, variada e complexa. Assim podemos, de forma preliminar, caracterizar a Geografia Agrária Brasileira. Dinâmica porque está na estrada há muito tempo e apenas nos últimos vinte anos transformou-se completamente e ganhou uma dimensão, porque não dizer, gigantesca. Variada por que trás para si distintos temas e enfoques. A complexidade é resultado desta dinâmica e desta variedade. A Geografia Agrária hoje não se restringe ao estudo da agricultura, mas é muito mais que isso.

Considerando-se estas características e diante do grande número de Grupos de Pesquisa que foram institucionalizados na última década no Brasil, tratar das questões metodológicas dos grupos é tarefa, no mínimo, abrangente.

O objetivo deste texto é demonstrar, ainda que numericamente, porque a Geografia Agrária brasileira é dinâmica, variada e complexa. Numericamente porque uma análise qualitativa demandaria tempo e acesso à informações bastante amplas que poderá ser almejada no futuro.

\section{O ENFOQUE ESCOLHIDO}

O objeto definido para análise foram os Grupos de Pesquisa. Um grupo está calcado em princípios básicos, conforme Spósito (2005). Seriam eles: a figura de um pesquisador; o caráter assumido pelo grupo no interior da Instituição que o sedia (pesquisa e ensino de graduação e pós-graduação); e finalmente, a temática, foco principal das pesquisas e estudos realizados. Esta proposta está sintetizada no esquema abaixo (figura 1 ).

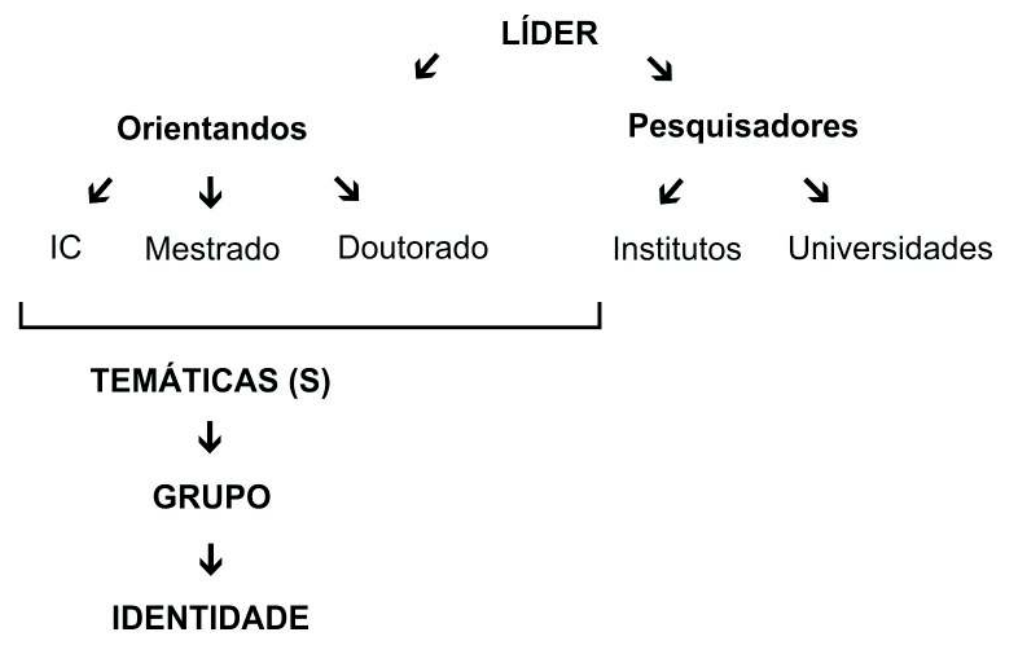

Figura 1: Esquema da Composição organizativa de um grupo de pesquisa a partir do pesquisador 
Sendo assim, pode-se pensar o grupo com a composição organizativa apresentada no esquema 1 sem esquecer que existirão eixos teóricos e metodológicos definidores dos estudos realizados.

Sob outra ênfase, pode-se identificar a organização dos grupos como no esquema 2 (figura 2), no qual é a temática o elemento central ou princípio norteador, através da qual os grupos se formam.

TEMÁTICA E EIXO TEÓRICO CENTRAL

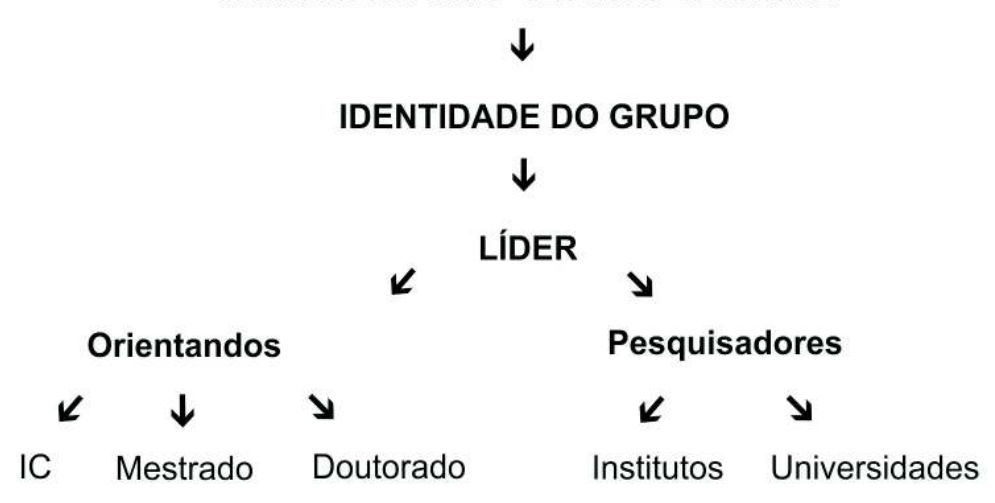

Figura 2 - Esquema da composição organizativa de um grupo de pesquisadores a partir da temática

Como dito anteriormente, utilizou-se como referencial para o levantamento das informações neste texto os dois princípios organizativos.

Entende-se que todo processo de formação e consolidação do Grupo de Pesquisa deve trilhar este caminho e que ele não é linear, mas com muitos meandros. Pode-se aferir que seja objetivo do Grupo a busca de uma identidade ou, no sentido inverso, é a partir de uma identidade, constituído por aproximação de pares em torno de um tema, que se cria um grupo.

Como a temática em debate é a Geografia Agrária, trabalhou-se com Grupos cuja identidade é dada pelos estudos do agro. Para contribuir com o debate em torno das questões metodológicas que caracterizam a Geografia Agrária Brasileira escolheu-se como tema os Grupos de Pesquisa em Geografia Agrária .

Diante do tema, foram definidas as estratégias de pesquisa. Para tanto, seria necessário o acesso aos Grupos, à produção deles e procurar identificar se as discussões metodológicas de cada um estavam refletidas nesta produção. As fontes de informações foram os sites (ou sítios) e páginas na internet de cada grupo.

Entretanto, havia outras questões. Quais são os grupos? Quem são os grupos? Trabalharíamos com aqueles que participam dos Encontros do ENGRUP? Teríamos a representação de todo o universo em questão?

Na busca destas respostas foi utilizada a fonte que temos hoje no país para identificação e consulta relativa a Grupos de Pesquisa - o Diretório dos Grupos de Pesquisa no Brasil do CNPq. Nesta fonte tivemos acesso aos grupos em funcionamento, certificados por suas instituições. Identificados os grupos efetuamos, em seguida, a busca dos sites ou páginas dos mesmos.

A pesquisa no Diretório pode ser efetuada de várias formas. Optou-se, primeiramente,

- pela busca por líderes - definidos como aqueles especialistas em Geografia Agrária, que trabalham com a temática do agro, e tudo a ele relacionado, e que circulam por congressos e reuniões científicas - Encontro Nacional de Geografia Agrária, Encontro de Grupos de Pesquisa, Encontro Nacional dos Geógrafos, Simpósio Internacional e Simpósio Nacional de Geografia Agrária.

. num segundo momento, foi realizada uma pesquisa por palavras e expressões peculiares aos estudos rurais. A partir daí, a curiosidade foi aguçada, pois o conjunto numérico e diverso 
de situações encontradas, quando se buscou a Geografia Agrária em Grupos de Pesquisa, foi muito superior ao esperado. Decidiu-se por aprofundar a pesquisa nesta fonte descartando-se a pesquisa em sites ou páginas dos grupos, ficando o Diretório de Grupos de Pesquisa do $\mathrm{CNPq}$ como fonte única.

\begin{abstract}
BOX 1
O que é o Diretório dos Grupos de Pesquisa?

O Diretório dos Grupos de Pesquisa no Brasil, projeto desenvolvido no CNPq desde 1992, constitui-se em bases de dados que contêm informações sobre os grupos de pesquisa em atividade no País. O Diretório mantém uma Base corrente, cujas informações são atualizadas continuamente pelos líderes de grupos, pesquisadores, estudantes e dirigentes de pesquisa das instituições participantes, e o CNPq realiza Censos bi-anuais, que são fotografias dessa base corrente.
\end{abstract}

As informações contidas nessas bases dizem respeito aos recursos humanos constituintes dos grupos (pesquisadores, estudantes e técnicos), às linhas de pesquisa em andamento, às especialidades do conhecimento, aos setores de aplicação envolvidos, à produção científica e tecnológica e aos padrões de inteno espaço (região, UF e instituição) e no tempo.

Os grupos de pesquisa inventariados estão localizados em universidades, instituições isoladas de ensino superior, institutos de pesquisa científica, institutos tecnológicos e laboratórios de pesquisa e desenvolvimento de empresas estatais ou ex-estatais. Os levantamentos não incluem os grupos localizados nas empresas do setor produtivo.

Fonte: Capturado de http://dgp.cnpq.br/, em $25 / 06 / 2009$

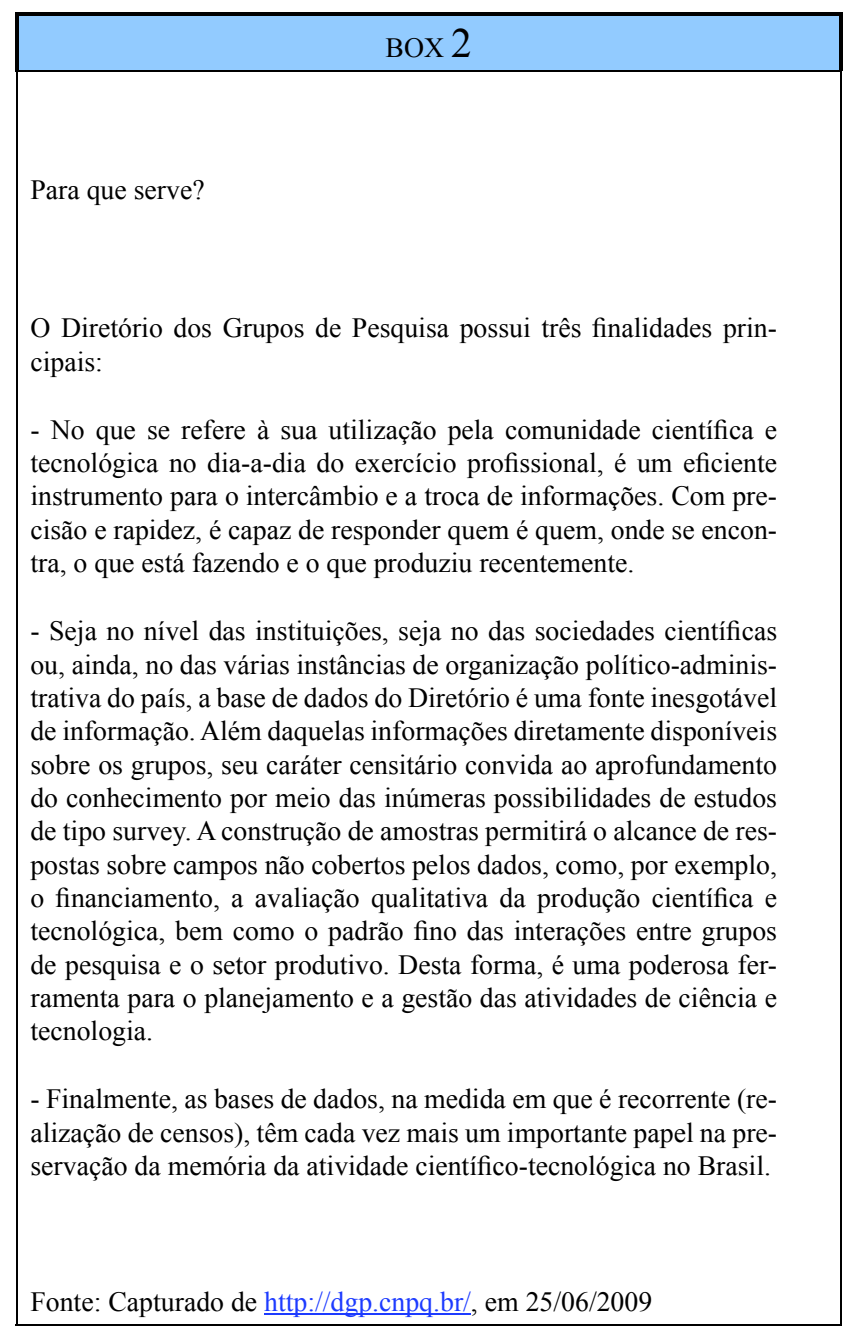

\section{OS PROCEDIMENTOS ADOTADOS}

Para a realização da pesquisa foram adotados os seguintes procedimentos:

. levantamento de informações sobre Grupos de Pesquisa ligados às temáticas: geografia agrária, agricultura, desenvolvimento rural, num primeiro momento. Posteriormente, incluíram-se na pesquisa os termos: rural, mundo rural, organização do espaço e desenvolvimento territorial. Eles apareceram nos primeiros resultados obtidos, enunciados nas linhas de pesquisa em andamento nos grupos, e entendeu-se que também poderiam ser representativos para identificação, além do que alguns deles são frequentes nos textos de geografia agrária na atualidade. A filtragem por palavras/expressões e líderes foi complementada pelos filtros: grande área do Grupo - Ciências Humanas e área - Geografia;

. organização de um banco de informações para armazenamento, tabulação e obtenção de dados relativos ao objeto estudado; 
. caracterização dos Grupos de Pesquisa por: instituição sede, localização por região geográfica, ano de formação, nome do Grupo, linhas de pesquisa e palavras-chave das linhas;

. apresentação e discussão dos resultados com proposições para estudos futuros.

\section{RESULTADOS - A GEOGRAFIA AGRÁRIA E A AGRICULTURA EM GRUPOS DE PESQUISA}

Para enfatizar destaca-se que o levantamento de informações sobre Grupos de Pesquisa teve como parâmetros:

. a geografia agrária - na perspectiva da Geografia, como ramo de especialização;

. a agricultura - na perspectiva de temática central ou de interesse de estudo;

. e o desenvolvimento rural - na perspectiva da aplicação e das relações com o setor público e produtivo.

Além disto, estas são palavras/expressões que marcaram, ao longo da história, os estudos do agro sob o ponto de vista da Geografia.

Os primeiros resultados obtidos para as palavras/expressões pesquisadas nos indicaram que em 2009 existiam registrados no CNPq o que se apresenta na tabela 1.

Tabela 1: Grupos de Pesquisa identificados por palavras/expressões

\begin{tabular}{l|l}
\hline PALAVRAS/EXPRESSÕES & $\mathbf{N}^{\circ}$ DE GRUPOS \\
\hline Geografia Agrária & 26 \\
\hline Agricultura & 35 \\
\hline Desenvolvimento Rural & 37 \\
\hline Rural & 56 \\
\hline Mundo Rural & 5 \\
\hline Organização do Espaço & 15 \\
\hline Desenvolvimento territorial & 16 \\
\hline
\end{tabular}

Fonte: Diretório de Grupos de Pesquisa no Brasil - 2009.

Observa-se que no primeiro conjunto de palavras/expressões, desenvolvimento rural é a que mais concentra numericamente grupos e isto pode ser explicado tendo em vista as repercussões e os setores de aplicação dos trabalhos dos grupos que são elencados no Diretório. Quando retiramos a Geografia Agrária (referência de ramo da ciência) como parâmetro de pesquisa, observamos que os estudos sobre a agricultura e desenvolvimento rural ultrapassam os limites desta - Geografia Agrária- e passam a ser temas de outros especialistas da Geografia.

O segundo conjunto de palavras/expressões nos indica que o mundo rural não é uma referência nos grupos levantados. O interessante é que quando efetuamos a pesquisa pela palavra rural temos um crescimento numérico e que reforça nossa hipótese de que quando não consideramos o ramo Geografia Agrária, a presença da temática rural se amplia consideravelmente e ultrapassa o limite da especialização. Na avaliação das linhas de pesquisa este fato será retomado.

Do levantamento realizado, após a eliminação das duplicidades, chegou-se a um total de 70 grupos de pesquisa que têm a geografia agrária, a agricultura, o desenvolvimento rural, o rural, o mundo rural, a organização do espaço e o desenvolvimento rural como norteadores de suas pesquisas e atuações.

Em relação ao nome dos grupos de pesquisa foi possível identificar que as referências a termos relativos ao agro são comuns. Os que mais se destacam estão representados na figura 3. É possível 
observar a presença de referências ao meio ambiente, aos estudos regionais, ao desenvolvimento e à gestão territorial, incorporados ao que se pode definir como estudos do agro. O meio ambiente é o grande destaque como se observará também em relação às linhas de pesquisa.

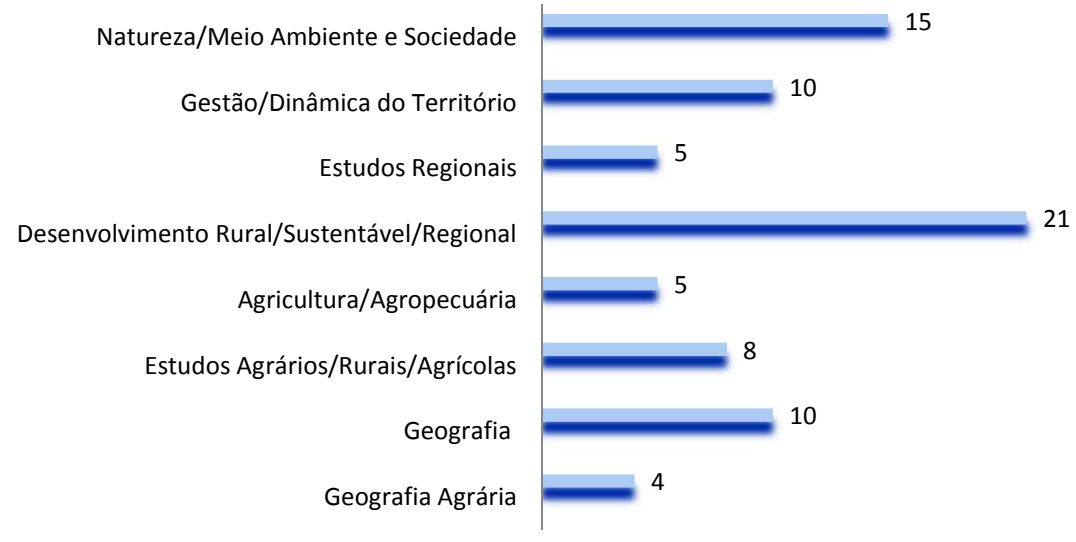

Figura 3 - Grupos de pesquisa por nome do grupo

Do total de 70 grupos levantados é possível indicar as instituições sedes dos mesmos, conforme a figura 4. As universidades federais são as que concentram $61 \%$ dos grupos selecionados, contra $36 \%$ nas universidades estaduais.

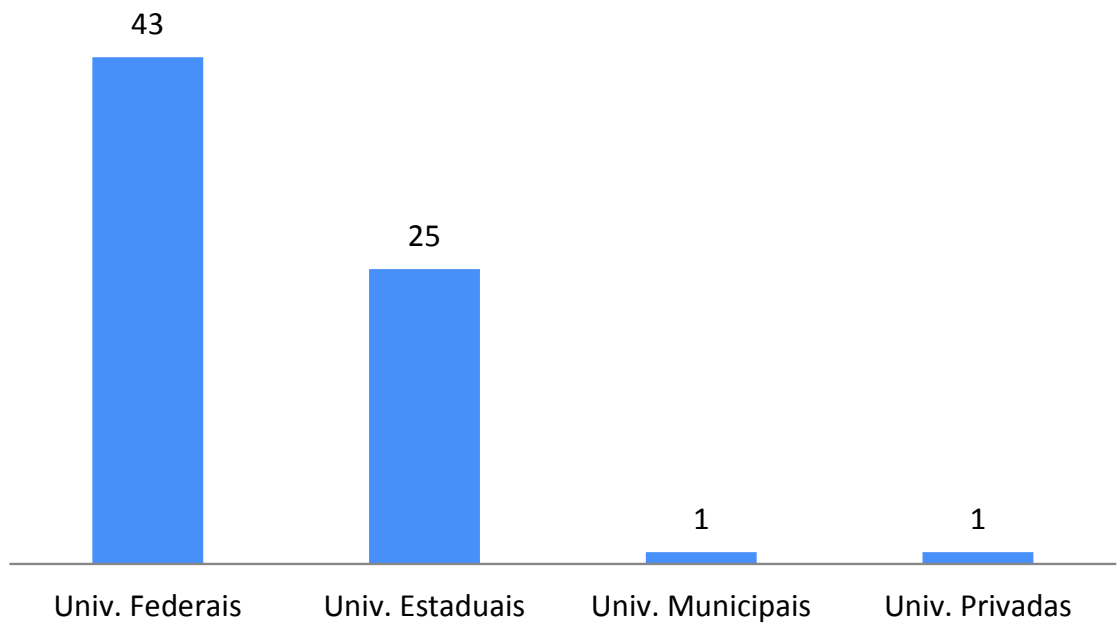

Figura 4 - Tipos de instituições sedes dos grupos de pesquisa

A presença em universidades federais majoritariamente pode ser explicada pela distribuição dos grupos no território nacional (figura 5).

Sediando três grandes universidades estaduais e universidades federais consolidadas, a Região Sudeste concentra 24 dos grupos encontrados. Muitos destes grupos têm como líderes geógrafos renomados e que são responsáveis atualmente pela dinâmica da Geografia Agrária brasileira, liderando alunos e pesquisadores nos grupos mais antigos. 


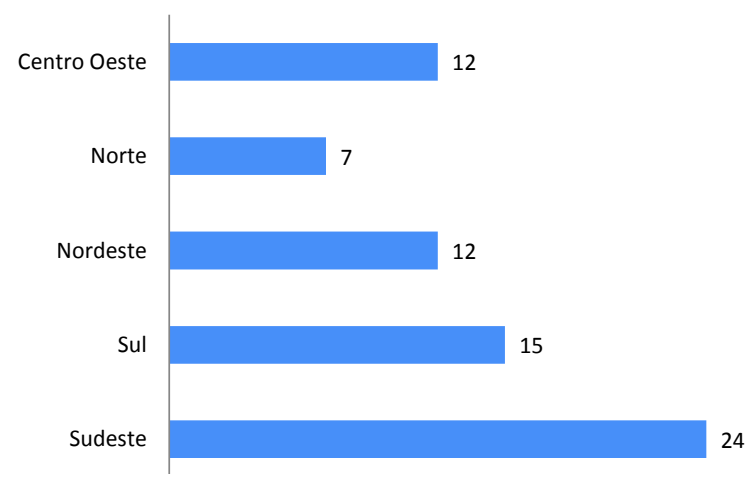

Figura 5 - Frequência dos Grupos de Pesquisa Por Grande Região Fonte: Diretórios dos Grupos de Pesquisa do Brasil, CNPq (2009).

O Centro-Oeste é a região de destaque já que tem em seu território 12 grupos, o que é significativo e pode ser explicado pela expansão das universidades federais. Aí se instalaram também os grupos com trajetória mais recente.

Na Região Norte encontramos 7 grupos, também recentes e cujas pesquisas estão voltadas prioritariamente para questões ambientais ligadas ao agronegócio, ocupação da fronteira e desenvolvimento rural sustentável.

A referência ao tempo de funcionamento dos grupos é bastante peculiar. O grande número de grupos de pesquisa que desenvolvem estudos rurais é resultado de uma expansão que ocorreu particularmente a partir dos anos 2000. Ter grupos de pesquisa institucionalizados e incluídos na base de dados do CNPq tornou-se uma necessidade acadêmica, especialmente após 1992 com a criação do Diretório de Grupos de Pesquisa, e foi estimulada pelas instituições de ensino superior, conforme pudemos verificar (Box1).

A figura 6 demonstra o movimento de surgimento dos grupos.

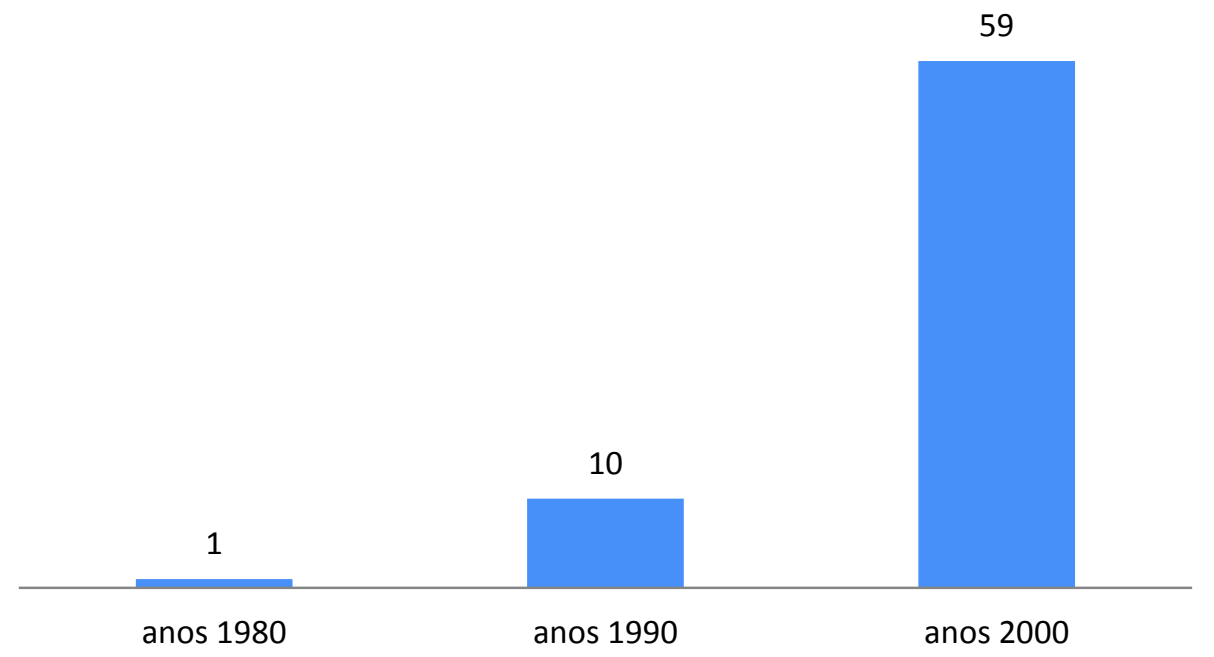

Figura 6 - Número de Gruppos de Pesquisa Formados por Período

É evidente o que significou a institucionalização dos grupos para os estudos do meio rural. Pôde-se identificar pelo levantamento que nos anos 80 um (01) grupo de pesquisa já realizava atividades no Brasil. Nos anos 90, a segunda metade da década marca o início do processo de 
constituição dos grupos, seguindo linearmente com o crescimento até o ano de 2009. A tabela 2 apresenta esta trajetória.

Tabela 2: Distribuição temporal e número de grupos institucionalizados

\begin{tabular}{l|l|l|l|l|l|l|l|l|l|l|l|l|l|l|l}
\hline 1983 & 1995 & 1996 & 1997 & 1998 & 1999 & 2000 & 2001 & 2002 & 2003 & 2004 & 2005 & 2006 & 2007 & 2008 & 2009 \\
\hline 1 & 1 & 2 & 2 & 3 & 2 & 4 & 2 & 10 & 3 & 4 & 5 & 6 & 4 & 17 & 4 \\
\hline
\end{tabular}

Fonte: Diretório de Grupos de Pesquisa no Brasil, CNPq, 2009.

Salta aos olhos o crescimento do número de grupos no ano de 2002 e 2008 . O que provavelmente explica esse crescimento, em 2002, é a presença neste ano de grupos que têm linhas de pesquisa centradas na temática do meio ambiente e no desenvolvimento sustentável. A análise da agricultura está inserida nesta discussão em linhas que relacionam agricultura e meio ambiente. Neste mesmo ano, em grupos que não seriam identificados pelos seus nomes como voltados à geografia agrária, mas sim como estudos ambientais, têm como linha de pesquisa a designada geografia agrária. Esta é uma evidência da complexidade do tema aqui estudado, que foi enunciada no início deste texto.

Também corroborando com essa hipótese, o ano de 2008 concentra o maior número de novos grupos. Há várias possibilidades de explicação para esse fato: demanda dos Programas de PósGraduação, exigências das instituições de fomento, surgimento de novos temas não atendidos pelos já existentes.

Os novos grupos que surgiram voltaram-se para os estudos de temas variados, permanecendo o princípio da diversidade e não da unidade como identificadora do que seria um estudo geográfico 90 sobre agricultura.

Observa-se que do conjunto de linhas levantadas é possível afirmar que há uma diversidade significativa em temas, o que reforça a hipótese da dinamicidade, variedade e complexidade dos estudos sobre agricultura na atualidade.

Avançando na discussão sobre as linhas de pesquisa trabalhadas, todas as que figuram nos 70 grupos levantados são citadas a seguir.

Linhas de Pesquisa:

A questão agrária e o meio rural;

A transformação do campo, implicações sobre a identidade e as novas formas de organização do espaço rural;

Abordagens teórico-metodológicas da geografia agrária;

Agricultura camponesa e produção familiar;

Agricultura e ambiente;

Agricultura e urbanização: cidades do agronegócio;

Agricultura familiar;

Agricultura familiar e campesinato;

Agricultura familiar e multifuncionalidade do espaço rural;

Agricultura familiar, pluriatividade e turismo rural no estado do Rio de Janeiro;

Agricultura sustentável;

Agroecologia;

Ambiente agrário e populações rurais das áreas úmidas do Brasil e do mundo;

Análise Geoambiental e políticas públicas;

Análise interdisciplinar do meio ambiente e desenvolvimento rural e urbano;

Análise populacional sul-americana;

Análise, planejamento e gestão dos espaços rurais e urbanos;

Análises territoriais e sustentabilidade;

Aproveitamento de recursos naturais e de resíduos pela agropecuária;

Área de agrária;

Áreas naturais protegidas no espaço urbano e rural;

Arranjos territoriais produtivos agrícolas;

As geografias da modernidade: geografia e gênero-família e trabalho; 
Assentamentos rurais;

Atlas dos conflitos fundiários no campo brasileiro;

Cidade campo: espaço e trabalho;

Cidade do agronegócio;

Circuitos espaciais de produção e círculos de cooperação;

Clima e produção do espaço agrário;

Clima e produção do espaço rural;

Comunidades rurais e populações tradicionais;

Conservação ambiental e turismo;

Desenvolvimento;

Desenvolvimento e economia solidária;

Desenvolvimento regional e geografia agrária;

Desenvolvimento regional e produção do espaço urbano e rural;

Desenvolvimento rural;

Desenvolvimento rural sustentável;

Desenvolvimento rural/agrário;

Desenvolvimento territorial;

Desenvolvimento, ambiente e território;

Dinâmica dos espaços agrícolas;

Dinâmica sócio-espacial da agropecuária;

Dinâmica sócio-espacial urbana e agrária;

Dinâmicas territoriais;

Dinâmicas territoriais agroindustriais na Amazônia Oriental;

Dinâmicas territoriais rurais e gestão do meio ambiente;

Dinâmicas territoriais, campesinato e populações ribeirinhas na Amazônia;

Educação geográfica no campo e imaginário rural;

Educação;

Espaço agrário e movimentos sociais;

Espaço agrário;

Espaço rural e movimentos sociais;

Espaço social e vínculos territoriais;

Espaços industriais e agroindustriais;

Estratégias de reprodução econômica e social de produtores rurais;

Estrutura fundiária;

Etnosustentabilidade e populações tradicionais;

Expansão agrária;

Formação sócio-espacial: mundo Brasil e regiões;

Geografia Agrária;

Geografia agrária e desenvolvimento sustentável;

Geografia agrária e rural;

Geografia da população;

Geografia e educação do campo;

Geografia rural;

Geografia, meio ambiente, cidadania, desenvolvimento urbano e rural;

Geoprocessamento e cadastro rural;

Geotecnologia aplicada a análise sócioespacial;

Gestão do espaço rural e meio ambiente;

Impactos das ligações urbano-rural nas mudanças no espaço regional;

Impactos sócio-ambientais do agronegócio

Impactos sócioterritoriais;

Logística de produtos agrícolas no território brasileiro;

Mapeamento da representação documental da história da luta pela terra;

Meio ambiente, educação e movimentos sociais no campo;

MMAPE - Mídia, mediações, ambiente e práticas de ensino;

Modelagem da produção vegetal;

Modernização agrícola e agronegócio;

Modernização campo e cidade;

Movimentos camponeses: espacialização, territorialização e mundialização;

Movimentos sociais agrários e transformação da estrutura fundiária; 
Movimentos sociais e organizações de luta pela terra;

Movimentos sociais no campo;

Multifuncionalidade do espaço rural;

Novas metodologias para o ensino da geografia agrária no Rio de Janeiro;

O campo, a cidade, a metrópole, o rural e o urbano no Brasil;

O desenvolvimento territorial percebido a partir das relações entre o urbano e o rural;

O ensino da geografia no contexto da educação do campo;

Organização do espaço agrário;

Organização dos espaços regional e rural/agrícola;

Organização e dinâmica do espaço rural

Organização social, instrumentos de intervenção e gestão pública;

Organização sócio-política no campo

Os efeitos sócio-espaciais dos sistemas agroindustriais;

Planejamento e desenvolvimento em agricultura familiar;

Planejamento turístico rural;

Pobreza rural e meio ambiente;

Política de desenvolvimento territorial;

Políticas públicas;

Políticas públicas e agricultura sustentável;

Políticas públicas, desenvolvimento rural e ruralidade;

Políticas públicas, dinâmica regional e desenvolvimento territorial;

Processos de modernização agrária

Produção animal;

Produção do espaço rural;

Produção do espaço urbano, rural e regional;

Produção e organização do espaço agrário;

Produção familiar;

Questão agrária no Brasil;

Questões fundiárias, modernização do campo e reforma agrária;

Redes agroindustriais;

Reforma agrária e assentamentos rurais;

Reforma agrária, assentamentos rurais e desenvolvimento territorial;

Relações campo-cidade;

Relações de gênero e território;

Representações da paisagem cultural da plantation canavieira no nordeste do Brasil;

Ruralidade e urbanidade;

Sistemas de produção agropecuária;

Técnica, tempo, espaço agrário;

Território e movimentos sociais;

Território, cultura e poder local;

Território, desenvolvimento e relação campo-cidade;

Território, economia, trabalho e desenvolvimento regional;

Territórios do saber: estudos das teorias e ensino de geografia;

Territórios paradigmáticos da geografia brasileira;

Transformações sócio-espaciais no rural fluminense;

Turismo rural;

Uso, manejo e conservação do solo e da água.

Observa-se que a variedade é grande. Se tomarmos alguns temas e buscarmos identificar como eles estão refletidos nas linhas, temos o demonstrado no quadro 1.

Pelo que está demonstrado até aqui, pode-se considerar o rural, o agrário e o desenvolvimento como expressões definidores da identidade da Geografia Agrária? Eles figuram entre os termos mais citados e como tais refletem o conteúdo do que seriam os estudos em Geografia Agrária ou os estudos geográficos sobre o agro, disseminados de distintas formas, conteúdos e qualificações. 
Quadro 1: Distribuição das linhas de pesquisa por grandes temas referenciados

\begin{tabular}{|l|l|}
\hline Agrário(a) [18]* & Questão; geografia; reforma; área de estudo \\
\hline Agricultura [9] & $\begin{array}{l}\text { Conjunto Familiar; pluriatividade; multifuncionalidade; relacio- } \\
\text { nada ao ambiente; relacionada à urbanização }\end{array}$ \\
\hline Ambiente [10] & $\begin{array}{l}\text { Meio; relacionado à agricultura; agrário; desenvolvimento terri- } \\
\text { torial; gestão territorial; dinâmica territorial }\end{array}$ \\
\hline Campo [11] & $\begin{array}{l}\text { Local de Transformação; modernização; relação cidade-campo; } \\
\text { educação; movimentos sociais }\end{array}$ \\
\hline Desenvolvimento [19] & Rural; regional; economia solidária; sustentável; territorial \\
\hline Modernização [4] & Do campo; agrícola; agronegócio; campo e cidade; agrária \\
\hline Rural [28] & $\begin{array}{l}\text { Relação cidade-campo; meio; espaço; desenvolvimento; geogra- } \\
\text { fia; turismo; transformações sócioespaciais; populaços; assenta- } \\
\text { mentos; imaginário; educação }\end{array}$ \\
\hline
\end{tabular}

* Número de citações do tema nas linhas de pesquisa

Fonte: Diretório de Grupos de Pesquisa no Brasil, CNPq, 2009.

Ampliando o escopo de análise e trabalhando com as palavras-chave que são indicadas por cada Grupo em cada linha de pesquisa na qual atua, a tabela 3 apresenta a frequência de algumas palavras encontradas e selecionadas, seguindo a trajetória do que vem sendo apresentado neste texto, ou seja, são palavras ou expressões que exprimem genericamente o agro como tema de pesquisa.

Tabela 3. Frequência de palavras-chave selecionadas

\begin{tabular}{l|l}
\hline PALAVRAS-CHAVE & FREQÜÊNCIA \\
\hline Agricultura & 22 \\
\hline Agricultura Familiar & 8 \\
\hline Ambiente & 8 \\
\hline Campo & 26 \\
\hline Desenvolvimento rural & 6 \\
\hline Geografia Agrária & 9 \\
\hline Modernização & 9 \\
\hline Movimentos sociais & 12 \\
\hline Políticas públicas & 4 \\
\hline Relação cidade-campo/campo-cidade & 6 \\
\hline Rural & 32 \\
\hline Ruralidade & 2 \\
\hline
\end{tabular}

Fonte: Diretório de Grupos de Pesquisa no Brasil, CNPq, 2009.

Rural, campo e agricultura são referências recorrentes e que podem ser os parâmetros para análises futuras. As perguntas agora seriam: o que é o rural para a Geografia Agrária? Como a agricultura é estudada na Geografia Agrária contemporânea? O campo é ainda um espaço em organização?

Diante da exposição apresentada que objetivou levantar elementos para a caracterização da Geografia Agrária no Brasil, tendo em vista a consulta ao Diretório de Grupos de Pesquisa do CNPq, entende-se ser necessário elaborar uma síntese do que foi trabalhado.

Para tanto, recuperou-se um esquema analítico (figura 7) proposto pelo Prof. José A. Filizola Diniz (1984, p.58) em seu livro Geografia da Agricultura, no qual ele esboça, com objetivo tipológico, o que seria o sistema da agricultura, constituído por elementos internos e externos. 
Do que pudemos levantar e avaliar em relação aos Grupos de Pesquisa, considerando os nomes dos grupos, suas linhas temáticas e palavras-chave, foi possível constatar que todo o conteúdo trabalhado está expresso na figura 1.

É inegável que temos hoje na Geografia Agrária brasileira Grupos de Pesquisa preocupados com questões econômicas, políticas, ecológicas, demográficas e culturais, e para, além disso, encontramos preocupações com os produtores rurais, com as suas produções e com o funcionamento do sistema agropecuário.

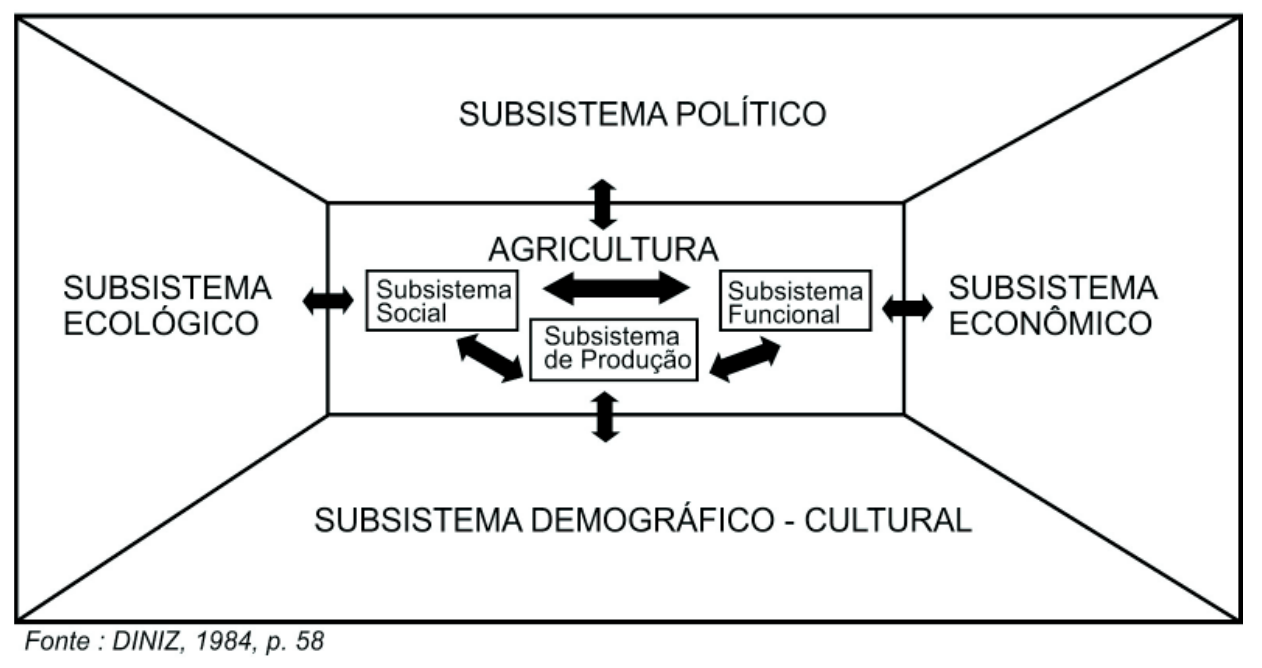

Figura 7 - Sistema da agricultura: elementos externos e internos

Portanto, fica claro que, avançados mais de vinte anos da proposta de Diniz (1984), sob nova roupagem, os estudos da agricultura realizados pelos Grupos de Pesquisa, hoje institucionalizados, refletem a preocupação com

uma das atividades mais complexas na superfície terrestre. [...] Inegavelmente, um estudo de caráter espacial pode contribuir enormemente para decifrar seus enigmas, pois não resta dúvida que variáveis essencialmente espaciais, como distância, padrão, forma, etc., integram o complexo agrário. (DINIZ, 1984, p. 15)

A pergunta que fica: o que é a Geografia Agrária brasileira hoje?

Muitas devem ser as respostas e muitas devem ser as buscas no sentido de obtê-las. Vale a pena essa busca? Como efetuá-la?

\section{CONSIDERAÇÕES FINAIS}

Sem querer neste momento nos aprofundarmos no assunto, mas para completarmos o raciocínio percorrido até aqui, consideramos importante traçar possíveis caminhos para avançarmos na discussão sobre a Geografia Agrária brasileira.

Devemos sempre lembrar que "os pesquisadores devem estar atentos para a natureza do conhecimento gerado em seu campo de estudos, assim como os fundamentos que norteiam as investigações" (THEÓPHILO e IUDÍCIBUS, 2005, p. 148). Para tanto, podemos tomar os Grupos de Pesquisa como fonte de análises. Eles, absolutamente, não são produção científica a ser analisada, bem como 
sua organização, formação, funcionamento, mas os produtos intelectuais por eles gerados o são.

Referimos-nos a artigos, trabalhos completos em anais de congressos, relatórios de pesquisa, iniciações científicas, dissertações de mestrado e teses de doutorado. $\mathrm{O}$ arcabouço para pesquisa é amplo e distinto, mas atingível.

Para análise do objeto em questão - a produção intelectual dos Grupos de Pesquisa de Geografia Agrária no Brasil - propomos a adaptação do modelo apresentado por Theóphilo e Iudícibus (2005) para os quais "a geração do conhecimento científico se processa em quatro níveis ou pólos: epistemológico, teórico, metodológico e técnico" (p.148). Para estes autores, os "pólos são concebidos como aspectos particulares do processo de conhecimento e espaço científico considerado como um campo dinâmico, sujeito à articulação dessas diferentes instâncias" (p. 148).

A Figura 8 expressa a concepção.

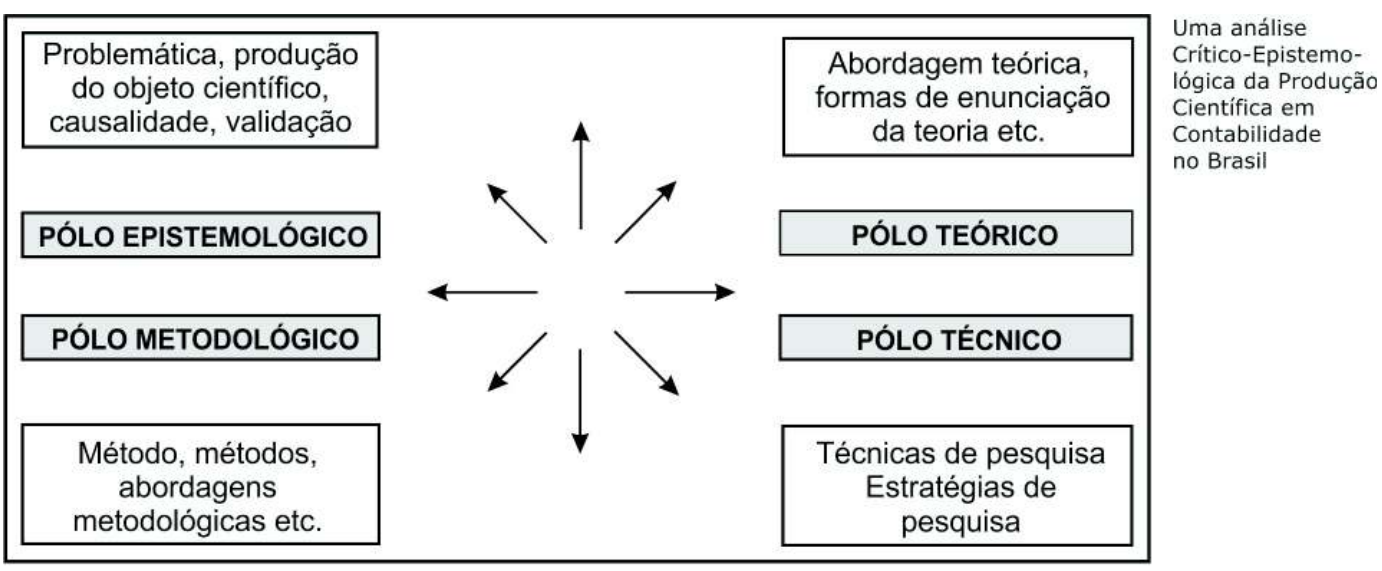

Figura 8 - Esquema paradigmático para análise dos trabalhos: espaço metodológico quadripolar Fonte: Theóphilo e Iudécibus, 2005.

Uma análise da produção dos Grupos de Pesquisas sob esta ótica permitiria um aprofundamento dos estudos sobre as abordagens teórico-metodológicas ainda não efetuada para a Geografia Agrária brasileira.

Da mesma forma, a análise a partir dos elementos internos e externos apresentados por Diniz (1984) permitiria uma avaliação das temáticas de pesquisa que compõem as linhas idealizadas pelos grupos. Definiríamos aqui as escolhas dos grupos em relação aos temas, apontando inovações, permanências e possíveis características de identidades.

São propostas de trabalho para um GRUPO que há algum tempo busca se conhecer e se autoavalia. Se conseguirmos congregar em um estudo os Grupos de Pesquisa que têm o agro como tema, há grandes possibilidades de definirmos qual a identidade deste GRUPO, contrariando a afirmativa feita no ENGA de 1996 em Diamantina-MG que traçava um futuro nada próspero para a nossa tão cara Geografia Agrária.

\section{REFERÊNCIAS BIBLIOGRÁFICAS}

DINIZ, J. A. F. Geografia da Agricultura. São Paulo: Difel, 1984. 278p.

SPÓSITO, E. S. Dinâmica econômica, fluxos e eixos de desenvolvimento. Avaliação da construção de uma temática. In: SPÓSITO, E. S. (org.) Produção do espaço e redefinições regionais: a construção de uma temática. Presidente Prudente: FCT/UNESP/GAsPERR. 2005. p. 53-83. 
THEÓPHILO, C. R.; IUDÍCIBUS, S. de. Uma análise crítico-epistemológica da produção científica em contabilidade no Brasil. UnB Contábil. UnB, Brasília, v. 8, nº 2, jul/dez. 2005. p. 147-175.

\section{Internet:}

CNPq. Diretório de Grupos de Pesquisa. Disponível em: http://dgp.cnpq.br/buscaoperacional/, acesso em 25/06/2009.

Trabalho enviado em fevereiro de 2011

Trabalho aceito em abril de 2011 